\title{
The Platelet-Lymphocyte Ratio Predict the Risk of Amputation in Critical Limb Ischemia
}

Murat Songur C*, Erdal Simsek, Omer Faruk Cicek, Kemal Kavasoglu, Sameh Alagha, Mehmet Karahan, Tugba Avcı and Irfan Tasoglu

Department of Cardiovascular Surgery, Turkiye Yuksek Ihtisas Training and Research Hospital Ankara, Turkey

\begin{abstract}
Background: The aim of this study was to PLR (paltelet-lymphcyte ratio) might represent significant prognostic indices in patients with CLI (critical limb ischemia) and might provide superior prognostic information.

Materials and methods: One hundred and fourty one patients presented with CLI to our hospital between February 2007 and June 2012 who could not have radiological or surgical revascularization and had medical treatment are included in our study ( $\mathrm{n}: 133)$. Primary end point was determined as amputation (limb survival) and all-cause death and separate analyses were performed.
\end{abstract}

Results: Out of the 133 patients in the study. There were a total of $28(26.9 \%)$ deaths and $46(34 \%)$ amputation over a mean follow-up of 46 months. The amputations were above ankle in $24(77 \%)$, below ankle in $7(23 \%)$ All patients were grouped in two, those undergone amputation and those without amputation. Diabetes mellitus, hemoglobin and platelet levels, mean PLR, PLR $\geq 160$ were strong univariable predictor of amputation.

Conclusion: Significant prognostic information can be obtained from routine blood results in patients with CLI. Stratification of CLI patients according to admission PLR should be considered in the limb survival analyses of future adjuvant and neoadjuvant trials to validate these findings.

Keywords: Platelet; Lymphocyte; Amputation

\section{Introduction}

Critical Limb Ischemia (CLI) is an entity with high mortality and high risk of limb amputation. Although treatment options, especially endovascular treatment possibilities, improved in the last decades, mortality and amputation rates are still high $[1,2]$.

Patients with CLI comprise a subset of high-risk patients with generalized atherosclerotic disease of the arterial tree. The presence of systemic atherosclerosis is associated with a low-grade systemic inflammatory response $[3,4]$. Previous studies have suggested that elevated preoperative C-Reactive Protein (CRP) levels [5,6], neutrophillymphocyte ratio (NLR), thrombocytosis and platelet agregation $[3,7,8]$ may also represent potential prognostic markers in peripheral arterial disease.

The aim of the study is to investigate the effect of the PLR value on amputation ratio in patients with CLI also PLR might represent significant prognostic indices in patients with CLI and might provide superior prognostic information.

\section{Material and Methods}

One hundred and fourty one patients presented with CLI to our hospital between February 2007 and June 2012 who could not have radiological or surgical revascularisation and had medical treatment are included in our study. These patients were assessed by the vascular team consisting of cardiologists, interventional radiologists and cardiovascular surgeons and accepted as ineligible for endovascular intervention or conventional surgery; thus getting medical therapy instead. All patients with CLI defined by the TASC II (Trans-Atlantic Inter-Society Consensus) for the management of peripheral arterial disease. The arterial anatomy of the lower extremities was assessed by digital subtraction angiography with use of either stepping techniques with a single contrast material bolus or multiple contrast material injections. Inclusion criteria were persistent rest pain for more than 2 weeks or ischemic skin lesions, ankle pressure below $50 \mathrm{mmHg}$ or, in patients with diabetes and incompressible vessels, absent palpable ankle pulses or toe pressure below $30 \mathrm{mmHg}$. Standard treatment included cilostazol, statins, analgesics, antithrombotic drugs (aspirin), cardiovascular risk factor control, hemorrheologic agents (such as pentoxifylline), local wound care and antibiotics, if indicated. The local ethics committee approved the study protocol.

Patients with infected ischemic wounds $(n=4)$, active cancer $(n=1)$, unstable coronary disease $(n=2)$ and steroid use $(n=1)$ were excluded from outcome analysis. Eight patients were excluded according to these criteria. Thus 133 patients were included the study.

Demographic characteristics, medical histories, risk factors, laboratory studies (Table 1) were collected by the research team using a standardized database. Prior surgical or percutaneous revascularization was documented (Table 1). Any subsequent surgical intervention was also documented as follows: major amputation (above the level of the ankle) or minor amputation(below the level of the ankle).

Primary end point was determined as amputation (limb survival) and all-cause death were performed. The effect of PLR on outcome was studied by constructing a receiver operating characteristic curve. Using a PLR cutoff of $\geq 160$, the area under the receiver operating characteristic curve was 0.65 (95\% confidence interval [CI] 0.55-0.75) (Figure 1).

${ }^{*}$ Corresponding author: Murat Songur C, Department of Cardiovascular Surgery, Turkiye Yuksek Ihtisas Training and Research Hospital Ankara, Turkey, Tel: +90 50537621 00; E-mail: drmuratsongur@hotmail.com

Received July 30, 2014; Accepted September 15, 2014; Published September 17,2014

Citation: Songur CM, Simsek E, Cicek OF, Kavasoglu K, Alagha S, et al. (2014) The Platelet-Lymphocyte Ratio Predict the Risk of Amputation in Critical Limb Ischemia. J Vasc Med Surg 2: 158. doi: 10.4172/2329-6925.1000158

Copyright: (c) 2014 Songur CM, et al. This is an open-access article distributed under the terms of the Creative Commons Attribution License, which permits unrestricted use, distribution, and reproduction in any medium, provided the original author and source are credited. 
Citation: Songur CM, Simsek E, Cicek OF, Kavasoglu K, Alagha S, et al. (2014) The Platelet-Lymphocyte Ratio Predict the Risk of Amputation in Critical Limb Ischemia. J Vasc Med Surg 2: 158. doi: 10.4172/2329-6925.1000158

Page 2 of 4

\begin{tabular}{|c|c|c|c|c|c|}
\hline Risc Factors & All Patients $\mathrm{N}=133$ & Non amputation $\mathrm{N}=87$ & Amputation $\mathrm{N}=46$ & Univariate OR & $\mathbf{P}$ \\
\hline Age (years) & $66.8(33-91)$ & $67.8(42-91)$ & $65.1(33-89)$ & $0.98(0.95-1.01)$ & 0.24 \\
\hline Age $>75$ years & $44(33.1 \%)$ & $30(34.5 \%)$ & $14(30.4)$ & $1.2(0.56-2.59)$ & 0.64 \\
\hline Male Gender & $111(83.5 \%)$ & $72(82.8 \%)$ & $39(84.8 \%)$ & $1.16(0.44-3.1)$ & 0.76 \\
\hline Diabetes & $55(41.4 \%)$ & $27(31 \%)$ & $28(60.9 \%)$ & $0.29(0.14-0.61)$ & 0.001 \\
\hline Hypertension & $61(45.9 \%)$ & $36(41.4 \%)$ & $25(54.3 \%)$ & $0.59(0.29-1.2)$ & 0.15 \\
\hline Hyperlipidemia & $62(46.6 \%)$ & $42(48.3 \%)$ & $20(43.5 \%)$ & $1.2(0.6-2.5)$ & 0.6 \\
\hline Current Smoker & $90(67.7 \%)$ & $63(72.4 \%)$ & $27(58.7 \%)$ & $1.85(0.87-3.9)$ & 0.11 \\
\hline Chronic Obstructive Pulmonary Disease & $56(42.1 \%)$ & $34(39.1 \%)$ & $22(47.8 \%)$ & $0.6(0.3-1.1)$ & 0.14 \\
\hline Previous Myocardial İnfarction & $33(24.8 \%)$ & $22(25.3 \%)$ & $11(23.9 \%)$ & $1.08(0.47-2.47)$ & 0.86 \\
\hline Stroke & $17(12.8 \%)$ & $9(10.3 \%)$ & $8(17.4 \%)$ & $1.1(0.3-4.2)$ & 0.8 \\
\hline Previus Vascular Surgery & $34(25.6 \%)$ & $18(20.7 \%)$ & $16(34.8 \%)$ & $0.46(0.2-1.03)$ & 0.06 \\
\hline Previus Stent & $8(6 \%)$ & $5(5.7 \%)$ & $3(6.5 \%)$ & $0.95(0.2-4.2)$ & 0.95 \\
\hline \multicolumn{6}{|l|}{ Medical Treatment } \\
\hline Statin Use & $23(17.3 \%)$ & $13(14.9 \%)$ & $10(21.7 \%)$ & $0.78(0.28-2.1)$ & 0.63 \\
\hline ASA Use & $45(33.8 \%)$ & $27(31 \%)$ & $18(39.1 \%)$ & $0.62(0.2-1.79)$ & 0.37 \\
\hline Cilastazol Use & $92(69.2 \%)$ & $65(74.7 \%)$ & $27(58.7)$ & $0.8(0.4-2.8)$ & 0.5 \\
\hline \multicolumn{6}{|l|}{ Laboratory Data } \\
\hline Urea (mg/dL). & $44.2(19-128)$ & $44.2(23-128)$ & $44.3(19-119)$ & $1(0.98-1.02)$ & 0.97 \\
\hline Creatinine (mg/dL) & $1(0.5-3.8)$ & $1.1(0.5-3.8)$ & $0.9(0.6-1.5)$ & $0.38(0.12-1.26)$ & 0.11 \\
\hline Hemoglobin (mg/dL) & $13.6(7.9-19.2)$ & $13.9(7.9-17.3)$ & $13(9-19.2)$ & $0.78(0.65-0.95)$ & 0.01 \\
\hline Platelet $\left(103 / \mathrm{mm}^{3}\right)$ & $325(73-959)$ & $298(73-865)$ & $374(108-959)$ & $1.02(1.01-1.05)$ & 0.02 \\
\hline White blood cells $(\times 109 / L)$ & $9.6(3.9-24)$ & $9.2(3.9-24)$ & $10.6(4.2-19.9)$ & $1.12(1.01-1.25)$ & 0.03 \\
\hline Neutrophil (×109/L) & $7.1(2.3-44.6)$ & $6.8(2.3-44.6)$ & $7.6(2.3-17.4)$ & $1.03(0.96-1.1)$ & 0.41 \\
\hline Lymphocyte (×109/L) & $2.2(0.5-20.5)$ & $2.4(0.5-20.5)$ & $1.9(0.8-3.6)$ & $0.7(0.45-1.14)$ & 0.16 \\
\hline PLR & $171.4(15.9-667)$ & $151.3(15.9-502.9)$ & $208.9(44.4-667)$ & $1.05(1.01-1.08)$ & 0.01 \\
\hline PLR $\geq 160$ & $58(43.6 \%)$ & $28(32.2 \%)$ & $30(65.2 \%)$ & $0.25(0.12-0.54)$ & $<0.001$ \\
\hline
\end{tabular}

Table 1: Baseline characteristics of patients. divided according to amputation.

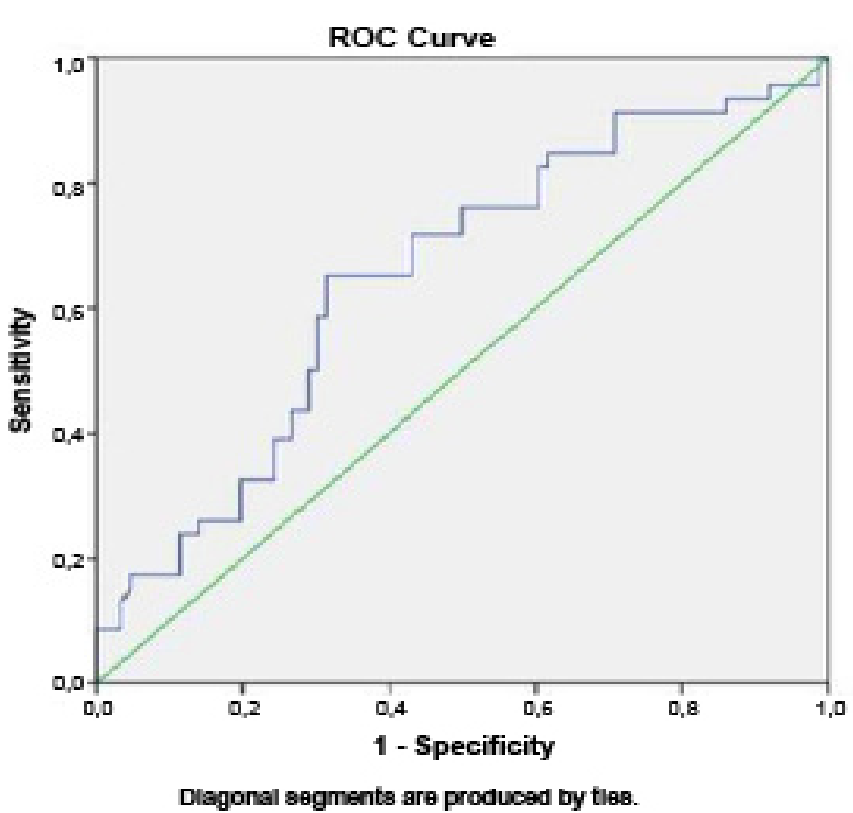

Figure 1: Using a PLR cutoff of $\geq 160$, the area under the receiver operating characteristic curve was 0.65 (95\% confidence interval $[\mathrm{Cl}] 0.55-0.75)$.

The admission complete blood count was recorded. Levels of hemoglobin $(\mathrm{Hb})$, white blood cells (WBC), platelet, neutrophil, and lymphocyte were measured using a Siemens Advia 2120 analyzer.

After the decision was made for patients as inoperable CLI, they were called in for follow-ups at the first, third, and ninth months and then with six-month intervals. Patients were contacted during routine check-ups at our centre on a periodic, but not uniform, basis. During the follow-up, the following events were registered: 1. Mortality for all causes, 2. Major or minor amputation. Latest statuses of the patients were ascertained via both phone and Social Security Death Index at the end of the study. 


\section{Statistical Analyses}

Continuous data were described using median, interquartile range (IQR) and 95\% confidence intervals (CI). Categorical variables were summarized as percentages. The effect of PLR on outcome was studied by constructing a receiver operating characteristic curve with amputation as the primary variable.

Estimations of risk were performed using Cox regression. Potential prognostic factors were entered into univariate regression models of midterm limb survival. Significant univariate correlates were then entered into a reverse stepwise multivariate regression model to test for independence. Analyses were performed using SPSS software. A p value $<0.05$ was considered statistically significant.

\section{Results}

Out of the 133 patients in the study, $83.5 \%$ were male and 16,5 $\%$ were female. The median age was 69 years and median followup was 39 months. 76 (57\%) patients had non-reconstructable (percutaneous or surgical revascularisation) arterial outflow vessels. $21(16 \%)$ patients were inoperable due to the comorbidities. $12(9 \%)$ patients didn't have suitable vein grafts. 5(3\%) patients didn't accept the revascularisation(radiological or surgical revascularisation). All of them had Rutherford classification 4 or 5 with multilevel disease.

Overall, there were a total of 28 (26.9\%) deaths and 46 (34\%) amputation over a mean follow-up of 46 months. The amputations were above ankle in 34 (74\%), below ankle in $12(26 \%)$.

The results of univariate limb survival analysis for each of the demographic and hematologic data are shown in Table 1. All patients were grouped in two, those undergone amputation and those without amputation. Diabetes mellitus, hemoglobine and platelet levels, mean PLR, PLR $\geq 160$ (Table 1) were strong univariable predictor of amputation.

When these 4 variables were included in a multivariate regression modeling, diabetes mellitus (OR,2,9; 95\%CI, 1.3-6,5 $\mathrm{P}=0.01)$, hemoglobin levels (OR, 0.9; 95\%CI, 0.75-1.15, $\mathrm{P}=0.5$ ), platelet levels (OR, 1; 95\%CI, 1-1.02, P=0.6), PLR $\geq 160$ (OR, 3.1; 95\%CI, 1.2-7.4, $\mathrm{P}=0.02)$ remained as independent factors associated with midterm amputation (Table 2).

\section{Discussion}

The findings of the present study demonstrate that PLR obtained from a universally available low-cost test (CBC with differential) provides relevant information regarding the risk of amputation in patients who are admitted with non-reconstructable CLI.

Chronic inflammation is both an etiological factor and physiological consequence of peripheral arterial disease $[3,8]$. Experimental models provide compelling evidence for the role of inflammation in the initiation, progression, and complication of atherosclerosis, confirmed in the clinical setting [9]. High levels of hs-CRP are correlated with angiographic coronary artery disease progression [10,11]. In the

\begin{tabular}{|c|c|c|c|}
\hline & Multivariate OR & S.E. & P \\
\hline Diabetes mellitus & $2.88(1.28-6.48)$ & 0.41 & 0.01 \\
\hline Hemoglobin $(\mathrm{mg} / \mathrm{dL})$ & $0.93(0.75-1.15)$ & 0.11 & 0.51 \\
\hline Platelet $\left(10^{3} / \mathrm{mm}^{3}\right)$ & $1.01(0.99-1.02)$ & 0.01 & 0.64 \\
\hline PLR $\geq 160$ & $3.1(1.22-7.4)$ & 0.46 & 0.02 \\
\hline
\end{tabular}

Table 2: Multivariate (Cox Proportional Hazards) Limb Survival Analysis (SE Standard error of regression coefficient, OR Ods ratio). peripheral vasculature, both hs-CRP $[7,10,11]$, fibrinogen and serum amyloid A [9] are related to the progression of atherosclerosis in peripheral arterial disease. Akinci et al. [12] demonstreated that circulating levels of acute phase reactants were associated with amputation risk in diabetic foot. Similarly, Violi et al. [13] reported that elevated levels of CRP were associated with poor long-term prognosis in patients with peripheral artery disease. Previous studies have shown that progression of atherosclerosis is associated with increased vascular events $[3,14]$. Progression of atherosclerosis and additional vascular events increase limb ischemia. Based on the findings of the present study, we also think that amputation may increase in patients with peripheral vascular disease with high inflammatory markers.

Thrombocytosis is commonly associated with a peripheral arterial disease and has been widely reported as an adverse prognostic marker [7]. The proinflammatory phase associated with systemic inflammation results in release of various immunological mediators such as interleukin (IL)-1, IL-3, and IL-6, which increase circulating platelet counts as a result of megakaryocyte proliferation $[15,16]$. It is well documented that subjects with pathologically increased platelet counts, that is, thrombocytosis, have an enhanced risk of thrombotic complications $[17,18]$. Experimental animal studies indicate that blood platelets both initiate atherogenesis and trigger its complications [19]. It is shown that, in healtly individuals with platelet count lower than normal, platelet aggregation increases when number of platelets increase $\left(>250 \times 10^{9} / \mathrm{L},>150 \times 10^{9} / \mathrm{L}[17,18]\right.$. Platelets play an important role in the progression of atherosclerosis. According to current research platelets interact with endothelial cells and leukocytes [20] and release inflammatory substances leading to adhesion and transmigration of monocytes [21]. These monocytes support inflammatory processes in the vessel wall promoting atherosclerotic lesions [22]. An elevated platelet count leading to an elevated PLR might therefore lead to an increase in vascular endpoints. Robless et al. found that whole blood platelet aggregation was significantly enhanced in PAD (Peripheric Arterial Disease) patients [7]. Also, previous studies have indicated that lymphopenia is associated with the progression of atherosclerosis. Lymphopenia may be caused by lymphocyte apoptosis in atherosclerotic lesions, which gradually increases with atherosclerotic burden. Likewise, a reduced lymphocyte count has also been associated with poorer prognosis [23-25].

Thrombocytosis and lymphocytopenia both correlate with the degree of host systemic inflammation, and the PLR reflects a novel marker incorporating both hematologic indices. Several studies has shown a relationship between the PLR and prognosis in colorectal and pancreatic cancer [26-30].

PLR value in vascular surgery is one of the subjects that have been recently studied, Gary and colleagues reported that PLR value of greater that 150 is a significant marker in PAD, similar to our study, PLR $\geq 160$ is associated with a high proportion of amputation in patients with PAD.

The limitations of our study include the possibility of selection bias, the relatively small number of patients with a highly prevalent disease, and the possibility of missing some outcomes using the Social Security Death Index. Only 1 measurement of admission full blood count and calculation of PLR was included in the analysis, and it was not possible to determine whether an acute and brief inflammation was responsible for the correlation observed. Additionally, inflammatory markers, such as C-reactive protein, myeloperoxidase, and interleukin-6, were not analyzed and compared to PLR. 
Citation: Songur CM, Simsek E, Cicek OF, Kavasoglu K, Alagha S, et al. (2014) The Platelet-Lymphocyte Ratio Predict the Risk of Amputation in Critical Limb Ischemia. J Vasc Med Surg 2: 158. doi: 10.4172/2329-6925.1000158

The results of the present study suggest that significant prognostic information can be obtained from routine blood results in patients with CLI. Stratification of CLI patients according to admission PLR should be considered in the limb survival analyses of future adjuvant and neoadjuvant trials to validate these findings.

\section{References}

1. Novo S, Coppola G, Milio G (2004) Critical limb ischemia: definition and natural history. Curr Drug Targets Cardiovasc Haematol Disord 4: 219-225.

2. Bertele V, Roncaglioni MC, Pangrazzi J, Terzian E, Tognoni EG (1999) Clinical outcome and its predictors in 1560 patients with critical leg ischaemia. Chronic Critical Leg Ischaemia Group. Eur J Vasc Endovasc Surg 18: 401-410.

3. Bhutta H, Agha R, Wong J, Tang TY, Wilson YG, et al. (2011) Neutrophillymphocyte ratio predicts medium-term survival following elective majo vascular surgery: a cross-sectional study. Vasc Endovascular Surg. 45: 227 231

4. Pereira IA, Borba EF (2008) The role of inflammation, humoral and cell mediated autoimmunity in the pathogenesis of atherosclerosis. Swiss Med Wkly. 138: 534-9.

5. Aboyans V, Criqui MH, Denenberg JO, Knoke JD, Ridker PM, et al. (2006) Risk factors for progression of peripheral arterial disease in large and small vessels. Circulation. 113: 2623-9.

6. Van Der Meer IM, De Maat MP, Hak AE, Kiliaan AJ, Del Sol Al, et al. (2002) C-reactive protein progression of atherosclerosis measured at various sites in the arterial tree: the Rotterdam Study. Stroke. 33: $2750-5$.

7. Robless1 P. A, Okonko1 D, Lintott1 P, Mansfield A. O, Mikhailidis D.P., et al. (2003) Increased Platelet Aggregation and Activation in Peripheral Arterial Disease. Eur J Vasc Endovasc Surg. 25: 16-22.

8. Spark JI, Sarveswaran J, Blest N, Charalabidis P and Asthana S. (2010) An elevated neutrophillymphocyte ratio independently predicts mortality in chronic critical limb ischemia. J Vasc Surg. 52: 632-636.

9. Zairis MN, Manousakis SJ, Stefanidis AS, Vitalis DP, Tsanis EM, et al. (2003) $\mathrm{C}$-reactive protein and rapidly progressive coronary artery disease-is there any relation? Clin Cardiol. 26: 85-90.

10. Zouridakis E, Avanzas P, Arroyo-Espliguero R, Fredericks S and Kaski JC (2004) Markers of inflammation and rapid coronary artery disease progression in patients with stable angina pectoris. Circulation. 110: 1747-1753.

11. Akinci B, Yener S, Yesil S, Yapar N, Kucukyavas Y, et al. (2011) Acute phase reactant predict the risk of amputation in diabetic foot infection. J Am Podiatr Med Assoc.101: 1-6.

12. Violi F, Criqui M, Longoni A, Castiglioni C (1996) Relation between risk factors and cardiovascular complications in patients with peripheral vascular disease. Results from the A.D.E.P. study. Atherosclerosis. 120: 25-35.

13. Kalay N, Dogdu O, Koc F, Yarlioglues M, Ardic I, et al. (2012) Hematologic Parameters and Angiographic Progression of Coronary Atherosclerosis. Angiology. 63: 213-270

14. Klinger MH, Jelkmann W (2002) Role of blood platelets in infection and inflammation. J Interferon Cytokine Res 22: 913-922.

15. Alexandrakis MG, Passam FH, Moschandrea IA (2003) Levels of serum cytokines and acute phase proteins in patients with essential and cancerrelated thrombocytosis. Am J Clin Oncol 26: 135-140.

16. Würtz M, Hvas AM, Kristensen SD, Grove EL (2012) Platelet aggregation is dependent on platelet count in patients with coronary artery disease Thromb Res. 129: 56-61.
17. Stissing T, Dridi NP, Ostrowski SR, Bochsen L and Johansson PI (2011) The influence of low platelet count on whole blood aggregometry assessed by Multiplate. Clin Appl Thromb Hemost. 17: 211-270.

18. Thaulow E, Erikssen J, Sandvik L, Stormorken H and Cohn PF (1991) Blood platelet count and function are related to total and cardiovascular death in apparently healthy men. Circulation 84: 613-617.

19. Gawaz M, Langer H, May AE (2005) Platelets in inflammation and atherogenesis. J Clin Invest 115: 3378-3384.

20. Lindemann S, Kramer B, Seizer P, Gawaz M (2007) Platelets, inflammation and atherosclerosis. Journal of thrombosis and haemostasis: JTH 5 Suppl 1 : 203-211.

21. Huo Y, Schober A, Forlow SB, Smith DF and Hyman MC (2003) Circulating activated platelets exacerbate atherosclerosis in mice deficient in apolipoprotein E. Nat Med 9: 61-67.

22. Duffy BK, Gurm HS, Rajagopal V, Gupta R, Ellis SG, et al. (2006) Usefulness of an elevated neutrophil to lymphocyte ratio in predicting long-term mortality after percutaneous coronary intervention. Am J Cardiol. 97: 993-996.

23. Park BJ, Shim JY, Lee HR, Lee JH, Jung DH, et al. (2011) Relationship of neutrophillymphocyte ratio with arterial stiffness and coronary calcium score. Clin Chim Acta. 412: 925-990

24. Seo SK, Cho S, Kim HY, Choi YS, Park KH, et al. (2009) Bone mineral density, arterialstiffness, and coronary atherosclerosis in healthy postmenopausal women. Menopause 16: 937-943.

25. Kwon HC, Kim SH, Oh SY, Lee S, Lee JH, et al. (2012) Clinical significance of preoperative neutrophil-lymphocyte versus platelet-lymphocyte ratio in patients with operable colorectal cancer. Biomarkers. 17: 216-222.

26. Smith RA, Ghaneh P, Sutton R, Raraty M, Campbell F, et al. (2008) Prognosis ofresected ampullary adenocarcinoma by preoperative serum CA19-9 levels and plateletlymphocyte ratio. J Gastrointest Surg. 12: 1422-1428.

27. Smith RA, Bosonnet L, Ghaneh P, Sutton R, Evans J, et al. (2008) The platelet lymphocyte ratio improves the predictive value of serum CA19-9 levels in determining patient selection for staging laparoscopy in suspected periampullary cancer. Surgery. 143: 658-666.

28. Smith RA, Bosonnet L, Raraty M, Sutton R, Neoptolemos JP, et al. (2009) Preoperative platelet-lymphocyte ratio is an independent significant prognostic marker in resected pancreatic ductal adenocarcinoma.Am J Surg. 197: 466472.

29. Bhatti I, Peacock O, Lloyd G, Larvin M, Hall RI (2010) Preoperative hematologic markers as independent predictors of prognosis in resected pancreatic ductal adenocarcinoma: neutrophillymphocyte versus platelet-lymphocyte ratio.Am J Surg. 200: 197-203.

30. Gary T, Pichler M, Belaj K, Hafner F, Gerger A, et al. (2013) Platelet-tolymphocyte ratio: A novel marker for critical limb ischemia in peripheral arterial occlusive disease patients. PLOS ONE. 8: 1-5. 